\title{
Reliability and durability from large heat recovery steam generators
}

\author{
M Pearson ${ }^{1 *}$ and $\mathbf{R}$ W Anderson ${ }^{2}$ \\ ${ }^{1} \mathrm{~J}$. Michael Pearson and Associates Company Limited, Terra Cotta, Ontario, Canada \\ ${ }^{2}$ Florida Power Corporation, St Petersburg, Florida, USA
}

\begin{abstract}
Experience with heat recovery steam generators (HRSGs) designed for larger-heat-input and higher-steam conditions highlights limitations in some features of traditional designs extrapolated from smaller HRSGs that operated predominantly continuously. Many combined-cycle units may be subjected to periods of regular overnight shut-down much earlier than expected and, unless anticipated during the initial design, there will be significant adverse impact on reliability and durability. Very premature problems already experienced on large HRSG designs in combined-cycle and cogeneration applications give an early warning that more widespread problems will arise as HRSGs are subjected to more thermal cycling. Problems that arise when inadequate attention is given to transient conditions over the full range of operation of the combined-cycle gas turbine unit, including at part loads, during shut-downs and restarts from diverse pre-start conditions, are highlighted. The paper gives examples of how the damage to HRSGs during shut-down and starts can be mitigated by minor modifications and sympathetic operating procedures and suggests how prudent purchasers can enhance reliability and lower lifetime costs at a small premium in installed cost by specification of appropriate design features. Other weaknesses which cause problems for operation and maintenance are discussed.
\end{abstract}

Keywords: heat recovery steam generators, two-shift operation, reliability, availability, durability

\section{INTRODUCTION}

Problems with unsatisfactory reliability and durability of some installed heat recovery steam generators (HRSGs) in large combined-cycle gas turbines (CCGTs) with highly rated gas turbines (GTs) stem from purchasers' paramount requirement for the lowest installed cost and high efficiency. High efficiency has driven rapid increases in GT exhaust flow and temperature imposed on HRSGs. The crucial importance of the lowest first cost has compelled the HRSG manufacturers to concentrate on lowering costs and discouraged the development of the more flexible designs necessary to accommodate the significantly more challenging conditions. There are design solutions but these will not materialize unless purchasers move the focus from low installed cost to lowest lifetime cost. Purchasers then

The MS was received on 29 October 1998 and was accepted after revision for publication on 4 February 1999.

*Corresponding author: J. Michael Pearson and Associates Company Limited, 1420 The Grange Sideroad, RR-1 Terra Cotta, Ontario, Canada LOP $1 N O$. need to seek quantitative verification that the difficult conditions experienced by large HRSGs during starts from any condition can be accommodated by the HRSG design configuration without risk of premature damage.

Some of the HRSG problems stem from traditional CCGT operating practices, which can produce extremely damaging conditions in parts of the HRSG. Others stem from a lack of consideration for the extremely damaging effects on the HRSG caused by large rapid changes in the GT exhaust temperature. Purchasers need to ensure that the aggressive start-up durations and load ramp rates promised by GT original equipment manufacturers (OEMs) and engineerprocure-construct (EPC) contractors are not at the expense of excessive damage to the HRSG.

The principal threats to reliability and durability in HRSGs are:

(a) low-cycle thermal fatigue (LCF),

(b) corrosion-related problems,

(c) other thermal-mechanical problems and

(d) other issues. 
All four categories are discussed in this report. However, LCF is given greater attention because it is the most difficult to overcome after the HRSG has been installed and can have a major impact on the reliability and the durability.

\subsection{Low-cycle fatigue}

HRSGs are subjected to very rapid large increases and decreases in the flow and temperature of the GT exhaust gas. The most severe changes occur during cold starts and following trips and subsequent hot restarts, but all starts from any condition cause some LCF damage to HRSGs.

HRSGs that have satisfactorily maintained continuous operation at high loads have, in some instances, suffered LCF failures after starts of the order of $10^{2}$. The premature failures are not associated with any one OEM but are the result of common design features and operating practices which have considerably intensified local thermal stresses. They highlight that there has often been little or no proactive consideration by the HRSG designer, the GT designer, the architect, engineer or EPC contractor, and the owner for the conditions which develop in the HRSG during starts and shut-downs. The failures that have occurred in HRSGs with particular features should be perceived as the precursor of more widespread problems that will affect many HRSGs as they accumulate more cycles.

LCF has been a major cause of forced outages and the predominant cause of widespread failures in pressure parts of all larger utility steam generators. The earlier failures at tight tube bends, at tube attachment welds to headers or to supports and restraints usually resulted from a lack of tube flexibility to accommodate larger than expected transient temperature differences. In later life these temperature transients initiated and propagated LCF cracks through the walls of many superheater and economizer headers, some of which required urgent premature replacements.

By applying some science to measure conditions occurring during starts and stops on the most vulnerable parts of conventional steam generators, and then applying thermal-mechanical finite element analyses to determine the peak temperature gradients and stresses during the most damaging transients, some more thermally flexible designs of very large coal-fired boilers have been successfully adapted by minor design modification and better operating techniques, to be capable of very large numbers of two-shift starts without LCF failures using procedures that can, when required, return a large unit to high load within 75 min of initiating the pre-start purge [1].

A similar scientifically based approach is now required for HRSGs. Critical design conditions in HRSGs are now quite similar to conventional boilers. However, all HRSGs behind current large industrial GTs are subjected to much more severe thermal transients because of the very large and rapid changes in the GT exhaust temperature and flow during starts and following shut-down of the GT. Furthermore, many designs of HRSG, and especially those with the more widely used horizontal gas pass arrangement, have stiff tube and header arrangements that can develop extremely damaging stresses if conditions cause tubes attached to the same headers to operate transiently at different temperatures.

\subsection{Corrosion issues}

Three corrosion-related potential problem areas are reviewed in Section 4.2:

(a) flow-induced corrosion (erosion-corrosion),

(b) cold end gas-side corrosion,

(c) management of water-side, feed and steam chemistry.

The first two can be eliminated by appropriate design. The third also requires design attention, especially if periods of two-shift operation are possible but, additionally, high standards of water-steam chemistry are required throughout operation to ensure durability and reliability of pressure parts. High-pressure (HP) steam generators are very unforgiving of even isolated water chemistry incidents.

\subsection{Other thermal-mechanical problems}

The following problems generally receive even less attention than pressure parts because they are perceived to involve low-stressed parts. However, they can deteriorate into persistent operation and maintenance challenges unless given the attention they deserve. Problems experienced include:

(a) flow-induced high-cycle fatigue (HCF) in many components in the gas path,

(b) LCF in casings of both hot and cold design and in expansion joints and

(c) over-spraying to saturation temperature during operation at part loads.

\subsection{Other issues}

Other issues include stratification of air during the pre-start purge of the HRSG.

\section{WHY FAILURES ARE NOW OCCURRING}

\subsection{Market pressure from customers}

The two paramount concerns of most purchasers of CCGT installations are low installed cost and high fuel 
efficiency. Compared with the very highly rated and troublesome large GTs, HRSGs have been perceived by many purchasers as well-established low-risk equipment. Selection of the HRSG is usually from the lowest bidder. To succeed in the very aggressive buyers' market, HRSG manufacturers have been compelled to concentrate on developing low-cost HRSG designs which just meet the requirements of purchasers' specifications and boiler design code. Design enhancements that improve reliability and durability at even a small cost are discouraged because most purchasers will give no credit for durability and select the lowest bidder.

\subsection{Higher GT exhaust temperatures and ramp rates}

Purchaser demand for higher combined-cycle efficiencies led to a rapid increase during the 1990s in the output and the exhaust temperature from large industrial GTs with consequent increases in the HRSG physical size, steam flow, pressure and especially temperature. These factors greatly increased the potential for early thermal fatigue damage in critical parts of the HRSG. As HRSG manufacturers were faced with these increasingly rigorous technical challenges, the market pressure to minimize cost continued unabated.

\subsection{Rapid extrapolation of HRSG designs beyond experience}

The early problems result from too much reliance by all on cyclic experience from HRSGs designed for much lower steam flows, pressures and temperatures operating with GTs with significantly lower exhaust temperatures. In general, HRSG designs were extrapolated with little or no regard for the effects of the more savage changes in the temperature and gas flow that occur with the more highly rated GTs during all starts and shut-downs. The HRSG manufacturers necessarily focused on the purchaser's primary concern for lowest first cost. Many HRSG designs were developed to comply with ASME Section I Power Boiler Code, which excludes any reference to LCF. Fatigue is mentioned in the British boiler code but is not mandatory and leaves the responsibility with the purchaser to define what fatigue analysis is required.

\subsection{EPC and turnkey contract strategies}

The strategy used by many owners for new CCGT projects of assigning responsibility for engineering, procurement and construction to a single EPC contractor has contributed to early problems in HRSGs. The EPC contractor's primary concerns are to minimize the installed cost, to meet guarantees which often include aggressive start-up durations set by the GT supplier and to avoid liquidated damages for late hand-over of

A06698 (C) IMechE 1999 the CCGT. This often leads to selecting the lowest-cost established design of HRSG, and only including in the balance of plant equipment list items necessary for base load operation. Purchaser-suggested enhancements for long-term reliability and durability, which often delay the schedule or add to cost, are generally resisted.

\subsection{Perpetuation of operating practices damaging to large HRSGs}

Development of CCGT start-up methods has been dominated by the GT manufacturers' concerns for the GT, the steam turbine and the desire to appease purchasers' demand for short start-up times from any condition. Little or no attention is given to the extremely damaging effects of rapid changes in the gas inlet temperature and flow to the HRSG during starts. Only in exceptional cases where the purchaser has been concerned for the durability of the HRSG when subjected to many starts has there been any attempt to understand how design features and methods of operation during starts and shut-downs can impact the LCF $[1,2]$. Predicting the LCF life for a new project requires dynamic simulation of the complete combined-cycle power train, steam and feed systems in conjunction with analysis of the most critical components to determine peak stresses during different operational manoeuvres. Recently, some large CCGTcogeneration units, installed originally for continuous operation, but now anticipating the requirement for two-shifting, have been instrumented with many thermocouples on tubes and headers of the HRSG to determine the actual conditions during shut-downs and during cold, warm and hot restarts. Data from a variety of operating manoeuvres were used to verify the boundary assumptions for finite element analysis of the most critical components. The peak stresses and cyclic life determinations were then used to develop modifications to the HRSG design and plant operating practices to soften the most damaging features.

\section{HOW TO REDUCE FUTURE FAILURES}

\subsection{Customer specifications for the design and methods of operation for new projects}

1. Exclude design configurations in the HRSG that increase the risk of damaging thermal stresses.

2. Specify the CCGT equipment necessary to avoid damaging thermal stresses in the HRSG, such as a superheater drain system, an auxiliary steam source and steam turbine bypass systems. 
3. Specify the design creep life and lifetime number of cold, warm and hot start cycles to include a generous margin to allow for uncertain future requirements.

4. Select the design code for the HRSG which significantly influences the thermal flexibility of the critical parts.

5. Ensure that analysis of all major transient conditions is completed and verify that the LCF life is compatible with the specified required life.

6. Specify automated sequenced starts and shut-downs to minimize trips and other damaging operational incidents.

\subsection{Feasibility of modifications to reduce the LCF damage to existing HRSGs}

1. Modifications to the HRSG to relieve stress in parts that are particularly vulnerable to LCF are sometimes feasible.

2. Upgrades to various balance of plant systems can often soften the more extreme conditions that cause excessive LCF damage to the HRSG including superheater drain systems, steam turbine bypass systems to the condenser and feedwater systems.

3. Installation of a stack damper reduces the rate of decay in the pressure in the HRSG and may be justified if frequent lengthy weekend shut-downs are anticipated.

\subsection{Avoidance by the owner of operating practices that cause high LCF}

1. For installed units, carry out early identification and mitigation of design and/or operating features that cause high LCF damage rates; this is important to preserve the LCF life for increased starts should they be required in the later life of the CCGT.

2. Eliminate trips, which are very damaging to HRSGs, as well as GTs, on large CCGT installations.

3. Minimize cold starts from ambient conditions as these cause the greatest LCF damage to the HRSG, particularly the superheater. Especially susceptible are superheaters using headers of P22 material with wall thickness exceeding $50 \mathrm{~mm}$. This includes many large CCGTs.

4. Avoid wasting most of the HRSG's LCF life quickly with aggressive cold starts, which are very occasional events.

5. Minimize the length of weekend shut-downs to maintain some HP in the HRSG. LCF damage per start increases significantly as the HP superheater and evaporator approach atmospheric pressure.
6. For two-shift and weekend shut-downs, box up the HRSG to maintain a pressure as high as possible for the restart.

7. Determine, by tests (measurement of conditions during major operating manoeuvres on similar CCGTs) or dynamic simulations in conjunction with the results from quantitative analyses, the operating conditions that cause acceptable LCF damage.

8. Establish minimum start-up durations from cold, warm and hot conditions and maximum loading rates after synchronizing and then later in the start-up from the results of analysis and not by speculation based on irrelevant experience. Startup durations offered by GT manufacturers and EPC contractors usually ignore conditions imposed on the HRSG when committing to short-duration start-ups and often result in accelerated LCF damage in the HRSG. Power purchase contracts should be based on GT loading profiles that avoid excessive damage to the HRSG. Aggressive reloading rates not only accelerate LCF failure of HRSG components but also increase the risk of CCGT trips.

9. Standardize operating procedures so that identical starts and shut-downs are performed by all shifts using the least damaging practices.

10. Automate all sequenced actions and controls during starts to minimize operator participation and the risk of error during rapidly changing conditions in the HRSG during the CCGT starts. Some large CCGTs perform routine starts to any pre-selected target load from any pre-start condition entirely automatically from a single button command. Specification of single button start and sequenced pre-start preparation of the plant, in conjunction with comprehensive pre-acceptance start-up trials, imposes a discipline on the EPC contractor to avoid cutting corners in design, specification or commissioning of equipment and controls which must function reliably during automatic start-up and shut-down trials before the CCGT is accepted by the owner.

\section{FAILURE MECHANISMS IN HRSGs}

The design features reviewed in this section are not intended to criticize any manufacturer and do not replicate any particular design. These features are presented merely as idealized examples to demonstrate the lessons learnt through hindsight, application of transient analyses and testing of actual HRSGs in service conditions which exceed those for which they were designed. All manufacturers are capable of producing designs that will avoid these problems if they are 
allowed a commercial environment in which to do so and the owner puts in place operating practices and a balance of plant design which recognizes the HRSG's unavoidable limitations when a large size, high temperatures and two-shift cyclic operation of CCGTs is desired.

\subsection{LCF in critical pressure parts of the HRSG}

Each design of HRSG has unique configurations and header dimensions which have different LCF damage rates if subjected to similar transient conditions. Analysis of all pressure parts of a complete large HRSG and LCF failures on other designs highlight three areas which should be assessed on all designs of large HRSG:

(a) HP superheaters and outlet manifold,

(b) HP steam drum and evaporator circuit and

(c) low-temperature economizers.

Other parts of some HRSG designs require assessment.

\subsubsection{HP superheater and HP outlet manifold}

Superheaters are subjected to a rapid increase in the GT exhaust temperature during starts from any condition. On large units the GT exhaust temperature ramps from $80{ }^{\circ} \mathrm{C}$ up to $450{ }^{\circ} \mathrm{C}$ in $5 \mathrm{~min}$ as the GT accelerates to synchronous speed. First the steam flow into the superheater header can be $200^{\circ} \mathrm{C}$ higher than the temperature of the outlet header of the superheater. Superheaters are designed to stress limits set by creep considerations. When creep is significant, there is a strong interaction between creep and LCF; thus, the creep life used at the end of the planned life of the HRSG must be limited to not more than 60 per cent to leave some allowance for LCF damage. For example, ASME Section III code case N47 indicates that, when

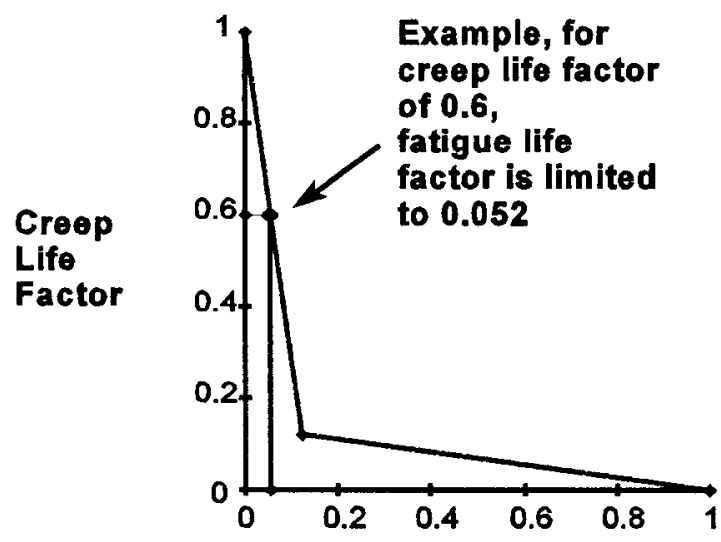

Fatigue Life Factor

Fig. 1 The design application of the ASME Section III Code Case N47 creep-fatigue interaction diagram the creep life factor is 0.6 , then the LCF life factor is limited to 0.052 (Fig. 1).

Factors which determine the severity of thermal stresses developed by high heat input to the outlet header include but are not limited to:

(a) the header thickness,

(b) the header diameter,

(c) differences in the tube temperatures,

(d) the tube diameter and pitch and

(e) the header temperature and transient steam temperature.

The header thickness can be reduced by use of materials with greater creep strength. Figures $2 \mathrm{a}$ to $\mathrm{c}$ are typical of many HRSGs designed for HP steam conditions of $10.5 \mathrm{MPa}$, and $540{ }^{\circ} \mathrm{C}$ using $\mathrm{P} 22$ $(2.25 \% \mathrm{Cr} 1 \% \mathrm{Mo})$ steel with a thickness of $65-70 \mathrm{~mm}$. Selection of P91 (modified 9\% Cr) steel reduces the header thickness by a factor of 2 or more (Fig. 2d). It should be noted that P91 may involve some small additional cost for more rigorous welding and quench cooling standards. There is now substantial international experience with the fabrication and installation of P91 headers.

The conduction of heat from tubes into the header has a significant influence on the temperature gradients and thus the thermal stress in the header at locations of the peak stress. A reduction in the diameter of the headers (without increasing steam velocities and pressure drops) by, for example, reducing the number of tubes per header and shortening the header or by providing two-inlet tees on each header is doubly advantageous. It enables thickness to be proportionally reduced and also reduces the circumferential temperature gradient established by conduction from the tubes (Fig. 2d).

For units already constructed, the only operational means available to minimize thermal stresses by hot steam into the superheater is to hold the GT load at a nominal block load until steam flow is established in the superheater and then to control the GT loading rate to ensure that the temperature difference between the steam temperature and the average header wall temperature remains at or below the initial difference on first admission of steam.

LCF is determined by the stress range which comprises tensile plus compressive stresses. In addition to severe heating ramps, superheaters are also vulnerable to very damaging quench cooling by condensate.

Condensation occurs in superheater tubes during every purge of the HRSG prior to GT ignition. This is because the GT exhaust temperature falls below the saturation temperature. Quantities are substantial during hot and warm starts and a repeat purge can fill the front panel tubes of the superheater. The condensate 


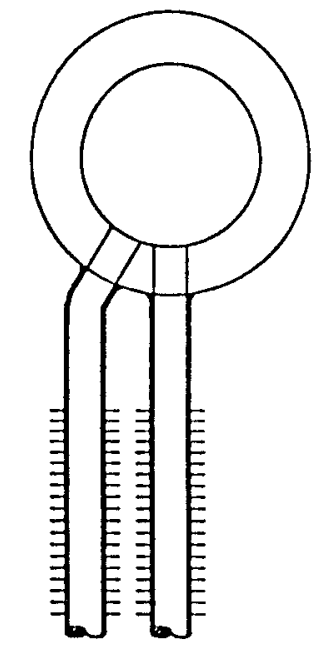

(a) Superheater outlet header with double
row of tubes-tubes in line to gas flow

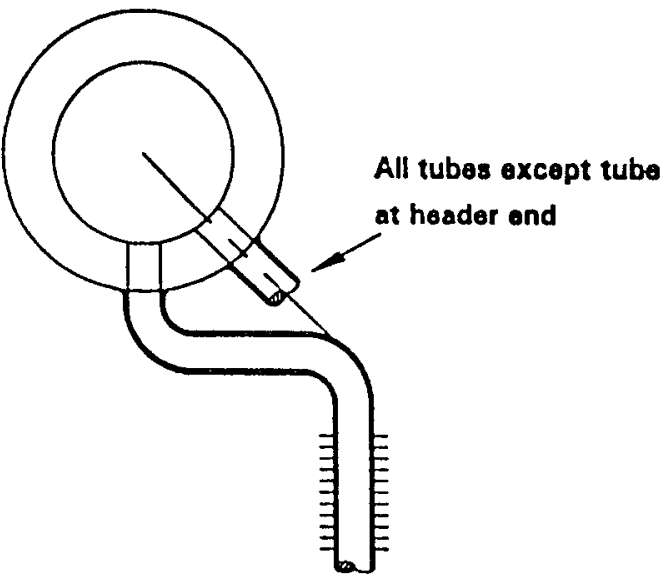

(c) Superheater outlet header-different connection for end tube

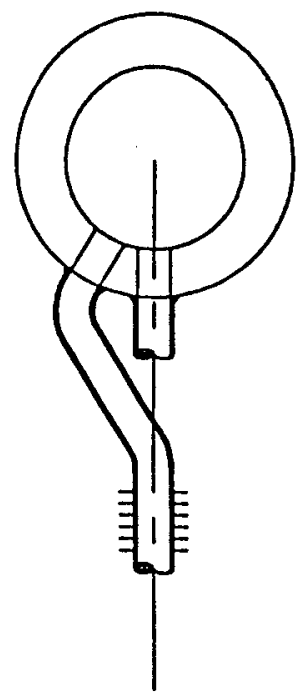

(b) Superheater header-one row of tubes with alternating connection to header

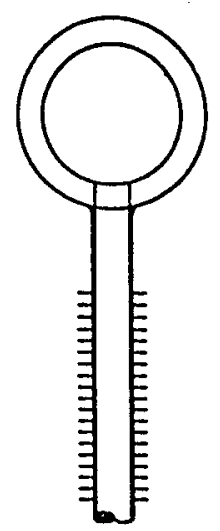

(d) Comparable superheater outlet header of P91 with two outlet tees per header

Fig. 2 Superheater header and tube arrangements

should be removed from the lower headers at the peak rate at which it forms to prevent pooling and flooding.

The crucial importance of adequately sized and correctly operated drains on superheaters has been overlooked on many large CCGT installations. Many units have no blow-down vessel for HP high-temperature drains from the superheater. Others have a blow-down vessel inadequately rated for the flow, pressure and temperature of drains from the superheater during hot restart purges. The drain installed on most designs of superheater was sized for maintenance purposes and is too small for clearing the condensate at the rate at which it collects.

Even where superheater drains are installed and con- nected to a blow-down tank, no guidance has been given by HRSG manufacturers or EPC contractors as to when and how they are to be used. Not surprisingly more often than not they are incorrectly used or not used at all during hot starts because many operators are unaware that conditions exist which cause substantial condensation in superheaters. In addition to forming a condensate during purge, Fig. 3 demonstrates the formation of a condensate during synchronization of a large GT as the firing rate is reduced to control the speed for synchronization.

To remove the condensate from the lower headers of vertically tubed HRSGs the lower headers must have an adequate bore in relation to their length and number 
of attached tubes to ensure that the tubes cannot flood. Measurements of the tube temperatures on an HRSG confirmed that, even with large bore lower headers and lower interconnecting transfer pipes, the condensate floods up the tubes during warm and hot starts when there are no facilities to drain the condensate (Fig. 4a). When the steam flow commenced, the tubes cleared progressively of the condensate as the steam flow and pressure drop were established (Fig. 4b). On HRSGs with very small bore long lower headers, a single small bore central drain cannot remove the condensate from

\section{Exhaust Temperature}

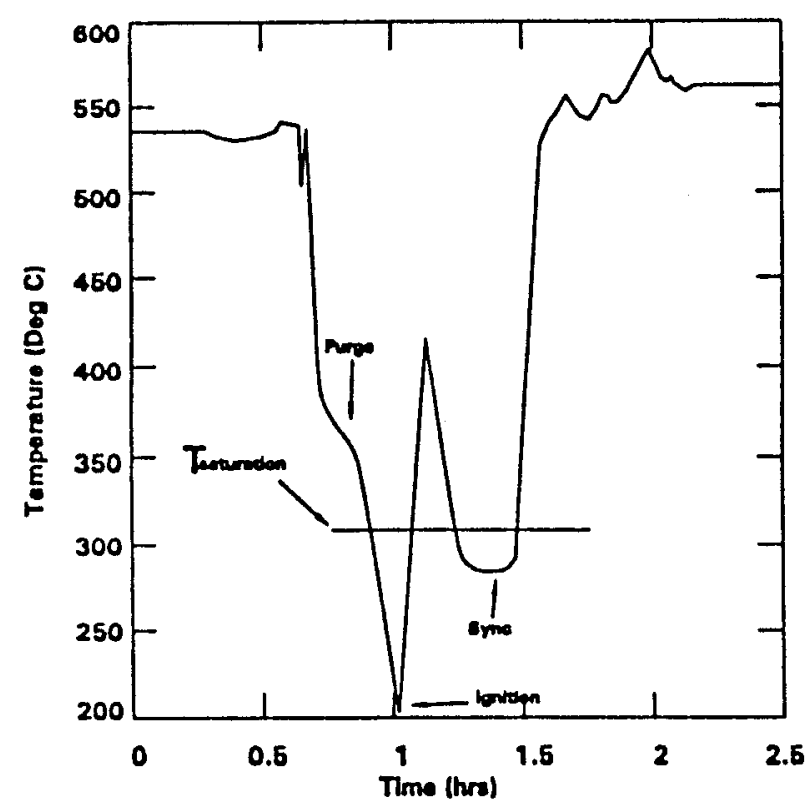

Final Superheater Outlet Steam Temperature (Deg C)

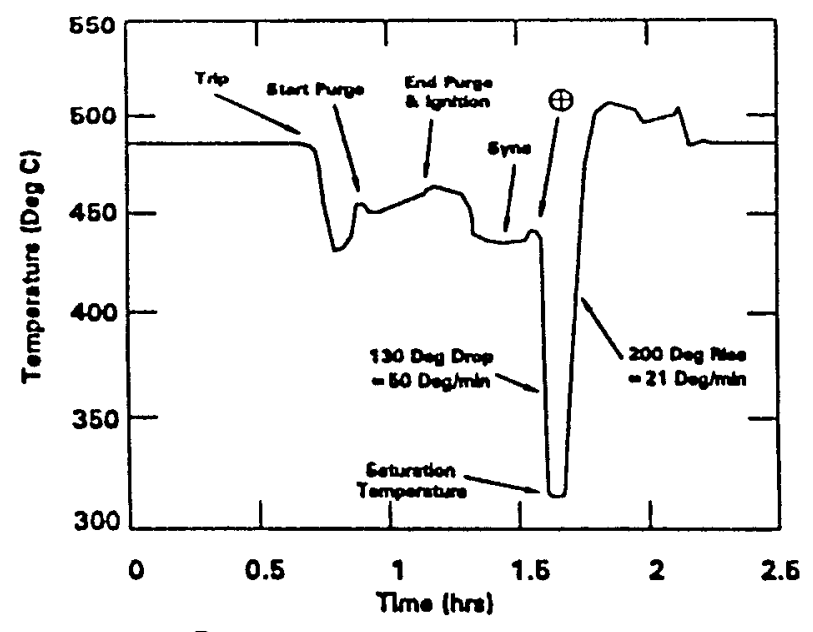

the more remote tubes which partially fill with the condensate (Fig. 4c). When the steam flow is first established, superheaters with inlet and outlet pipes connected to one end of the headers progressively clear the condensate from the tubes closest to the end pipe connections, creating a further transient discrepancy between the tube temperatures along the headers (Fig. 4d).

When the lower headers are of small bore and remain undrained during the purge, the initial condensation quickly floods the tubes, creating a seal between the HP
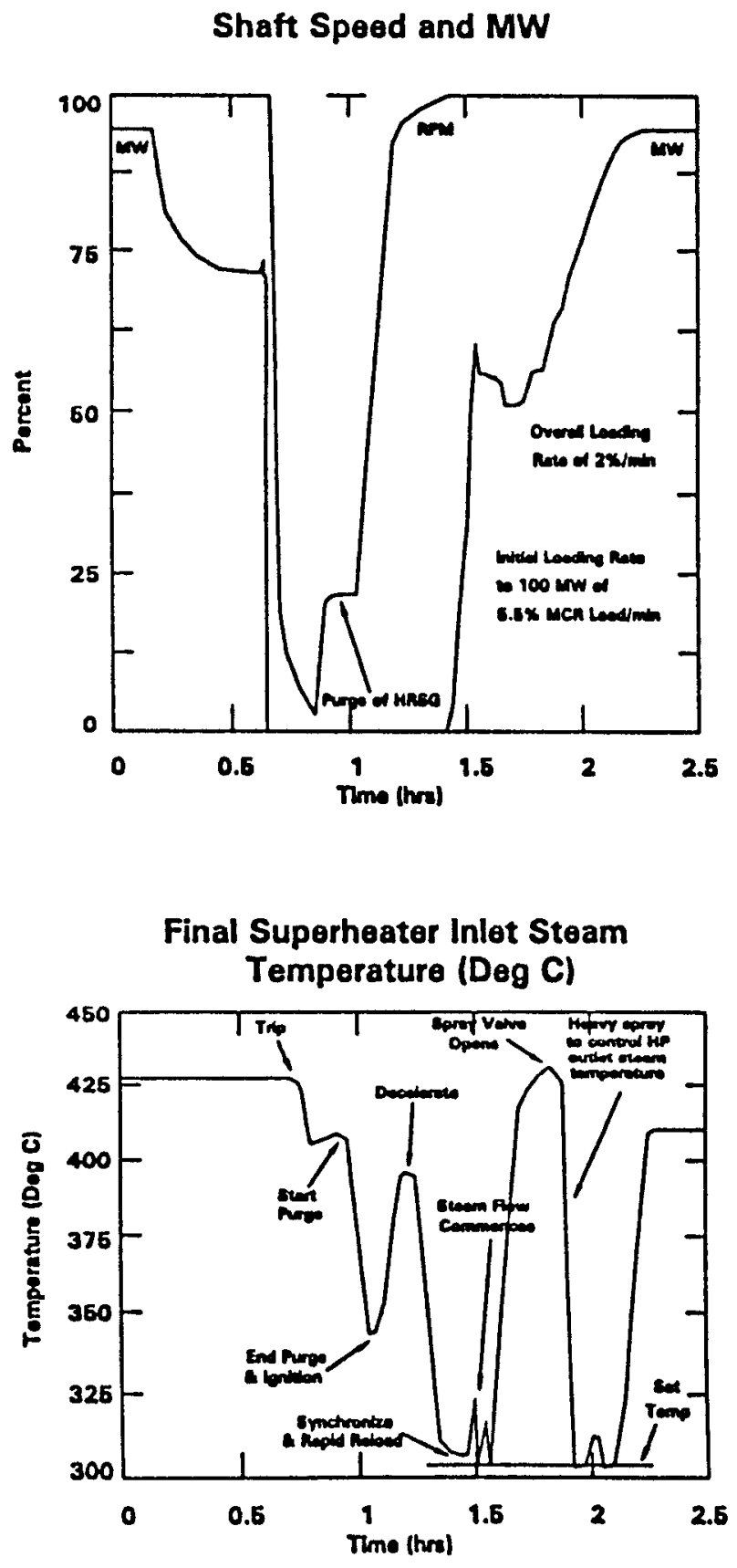

Fig. 3 Trip and immediate restart. The condensate is not drained from the superheater during purge (GT initial loading rate, 5.5 per cent of the maximum continuous rating per minute) 


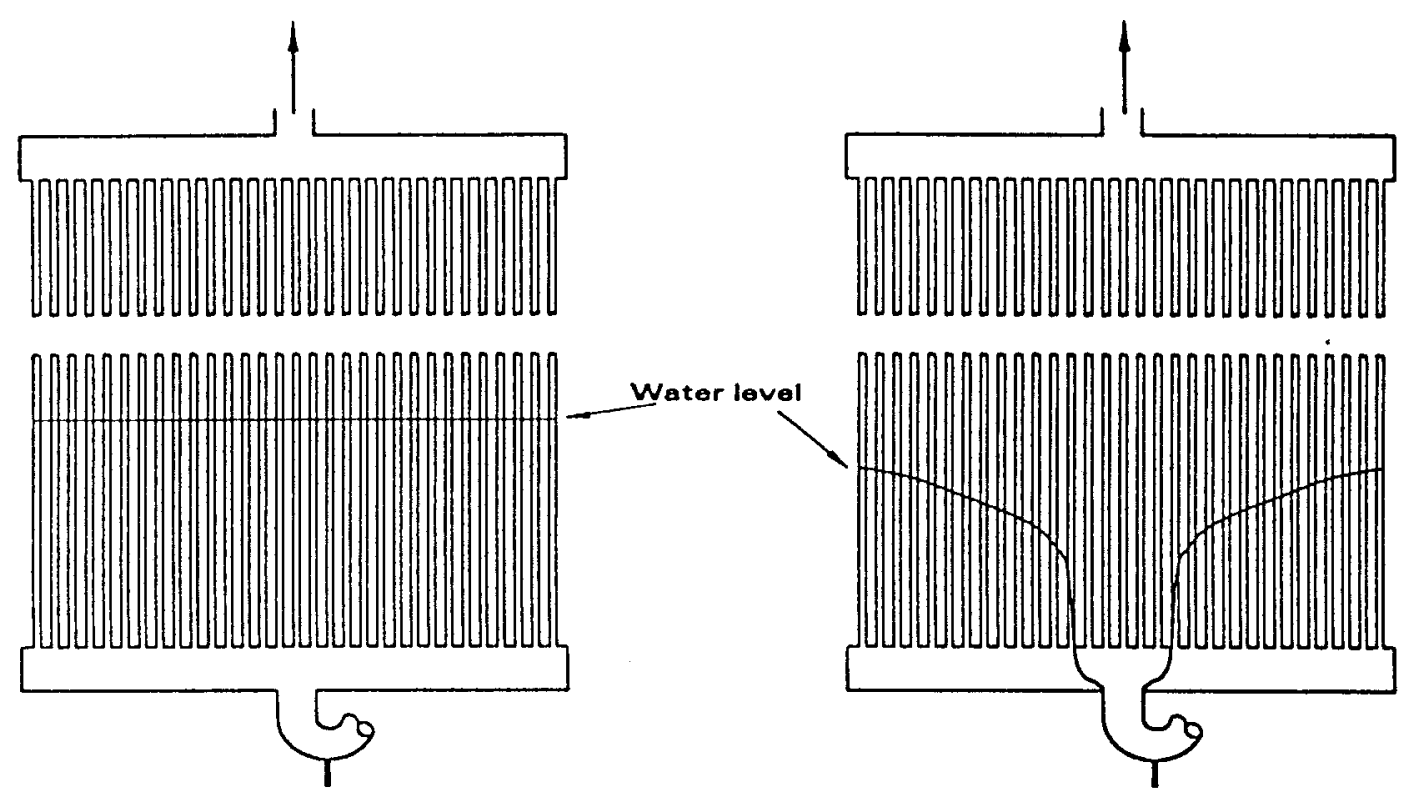

(a) Large volume lower headers. Condensate at end of purge.

(b) Condensate after first steam No drainage during purge flow established
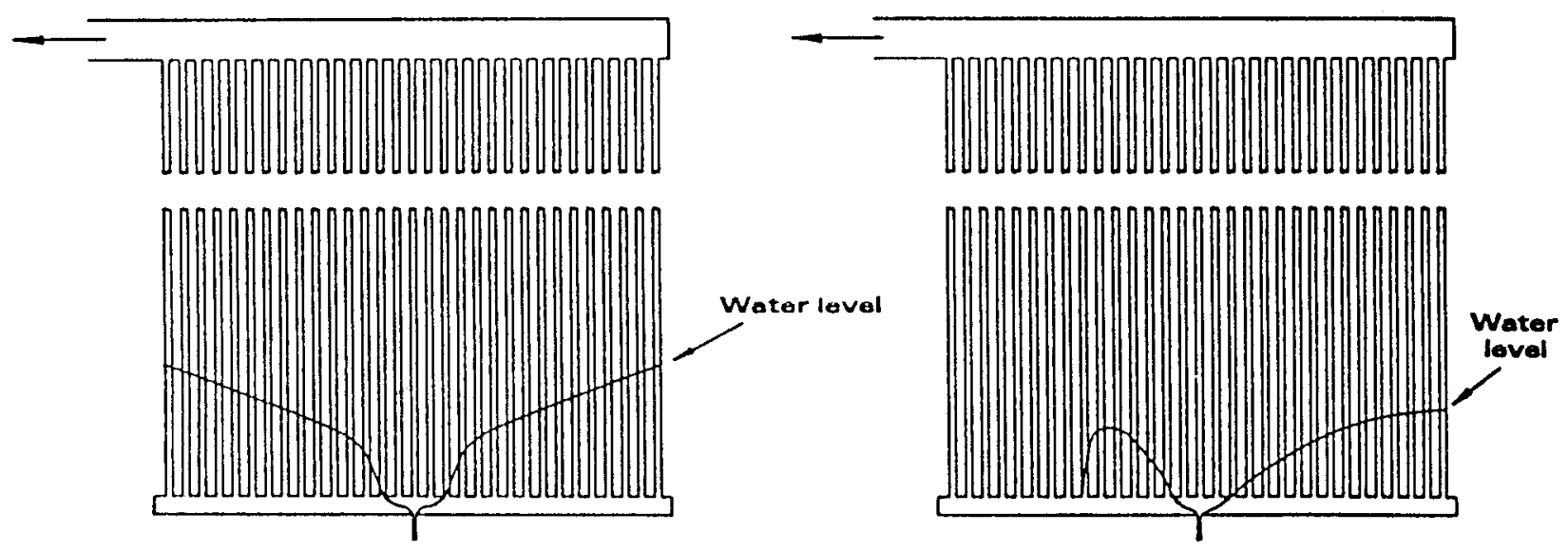

(c) Small bore lower headers. Drain used during purge

(d) Drain used, condensate after first steam flow established

Fig. 4 Condensation in the superheater tubes during purge

drum and the superheater outlet manifold. Further condensation reduces the pressure in the superheater outlet manifold pressure side of the water-sealed tubes more rapidly than the HP drum pressure. This pushes the column of water up the discharge tube row of the final superheater (Fig. 5). A similar phenomenon occurs in the primary superheater although the condensation rate is lower as the gas temperature rises through the superheater. Instances have been observed on longer purges where a subcooled condensate was pushed from the primary superheater tubes into the final superheater section.

There are two adverse implications of not removing all the condensate from the superheater tubes before the steam flow is established. Firstly, the condensate, which is possibly still subcooled, is ejected in large quantities into the outlet header and pipe manifold where it quench cools hotter material. On hot restarts after trips, the temperatures of the outlet header and manifold can be more than $200{ }^{\circ} \mathrm{C}$ above the saturation 
temperature. During warm starts, the outlet header temperature will be close to the saturation temperature but the outlet manifold temperature is still substantially higher.

Figure 3, recorded on an HRSG during a restart after a trip, highlights the severe quench that occurred in the superheater outlet pipe at the thermowell pocket when the initial steam flow transported large quantities of the condensate and dropped the superheater outlet temperature by $130{ }^{\circ} \mathrm{C}$ at $50^{\circ} \mathrm{C} / \mathrm{min}$ to saturation. The condensate took 2 or $3 \mathrm{~min}$ to clear completely. The initial GT loading rate was very high ( 5.5 per cent of maximum continuous rating per minute), causing a rapid rise of $200^{\circ} \mathrm{C}$ in the superheater outlet steam temperature at $21^{\circ} \mathrm{C} / \mathrm{min}$. As on most HRSGs, the outlet headers are P22 material with walls more than $50 \mathrm{~mm}$ thick. This event was a very severe thermal cycle. This event was

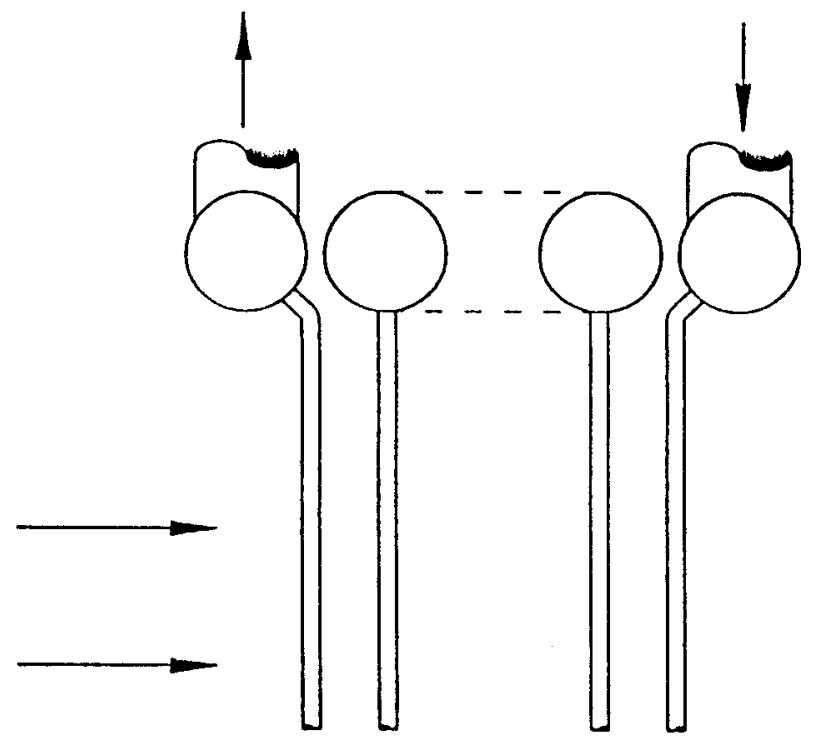

Gas Flow

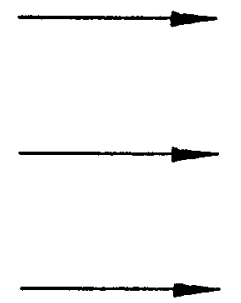

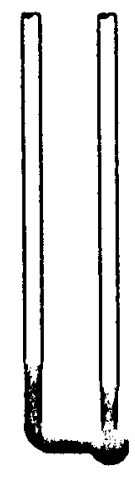

Final

Supertieator

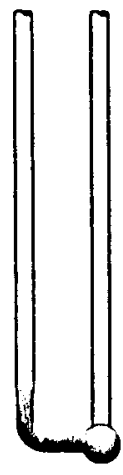

Pilmary

Suporthoator not an operator error; the unit was operated strictly within the designers' recommended limits. No cautionary advice was provided by the designers that condensation occurs even during purges prior to very hot restarts.

Figure 6 is the condition which occurs when the condensate is completely drained from the superheater at ignition before the steam flow commences for a repeat of the trip restart in Fig. 3. The reduction in LCF damage is very substantial.

Secondly, tubes transiently have different average temperatures because they do not become clear of the condensate precisely simultaneously. Some tubes are clear of the condensate and are cooled by the steam flow while others have part of the tube immersed in the condensate at the saturation or lower temperature, and other parts are stagnant and at the gas temperature. Designs which have stiff tube arrangements connected to the

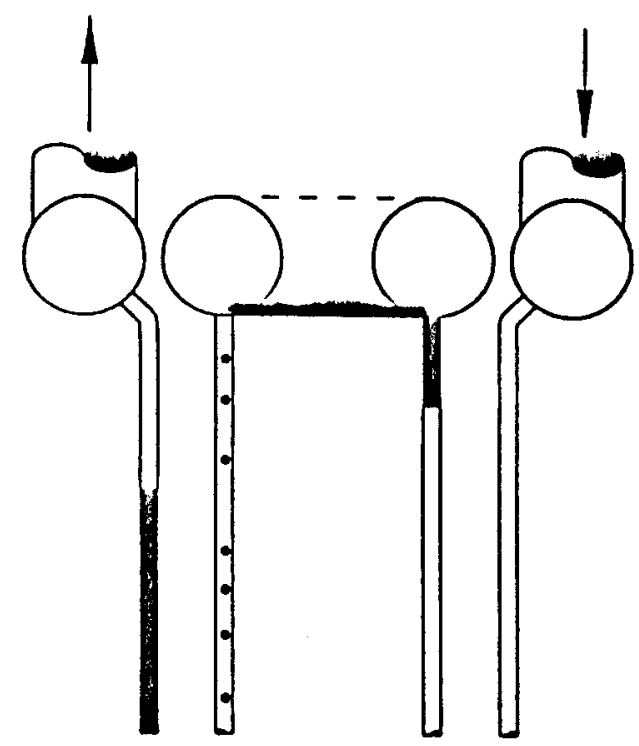

\section{Early part of purge}
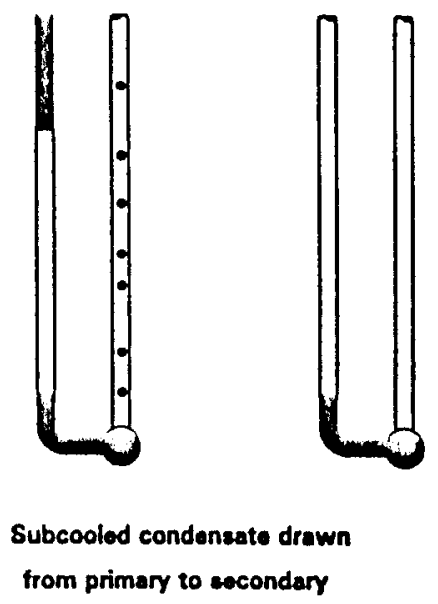

Latter part of purge

Fig. 5 The condensate behaviour in the superheater during purge 


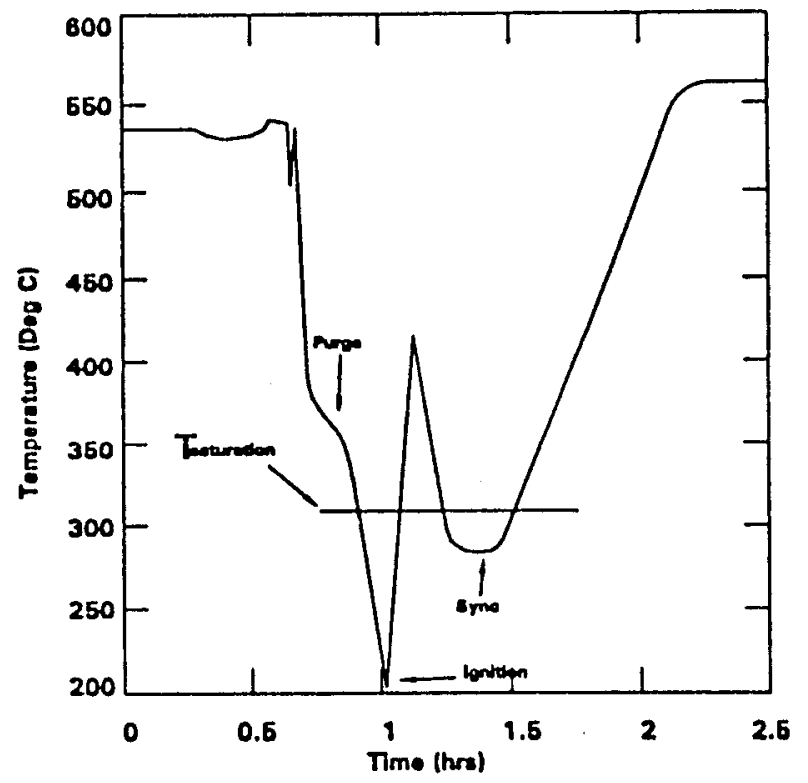

Final Superheater Outlet Steam Temperature (Deg C)

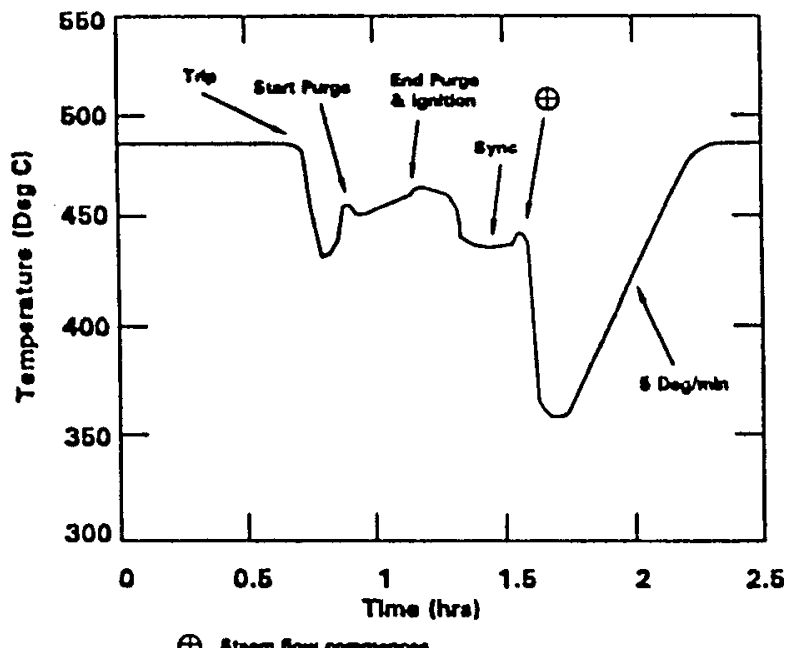

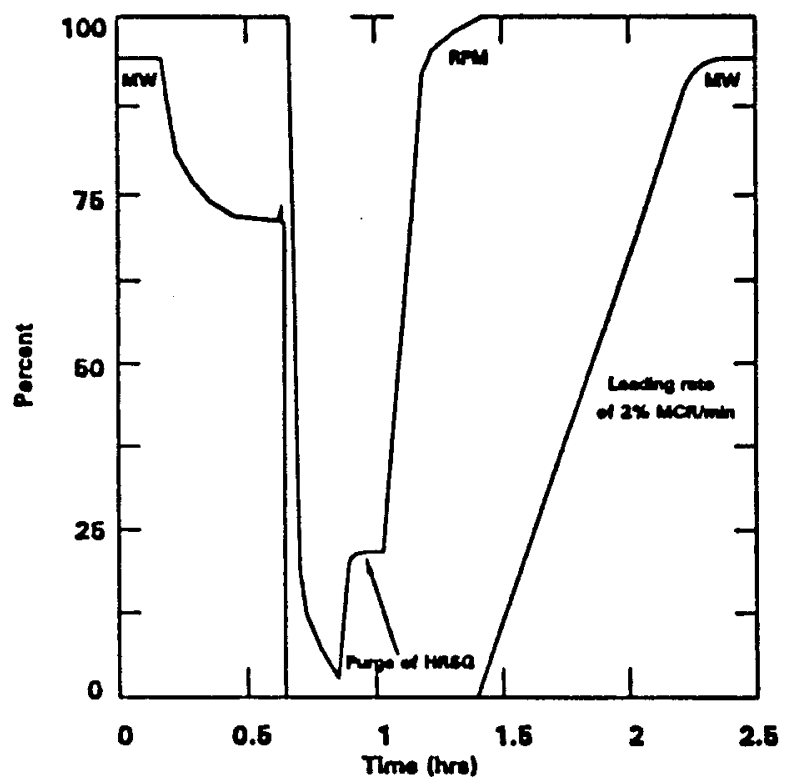

Final Superheater Inlet Steam Temperature (Deg C)

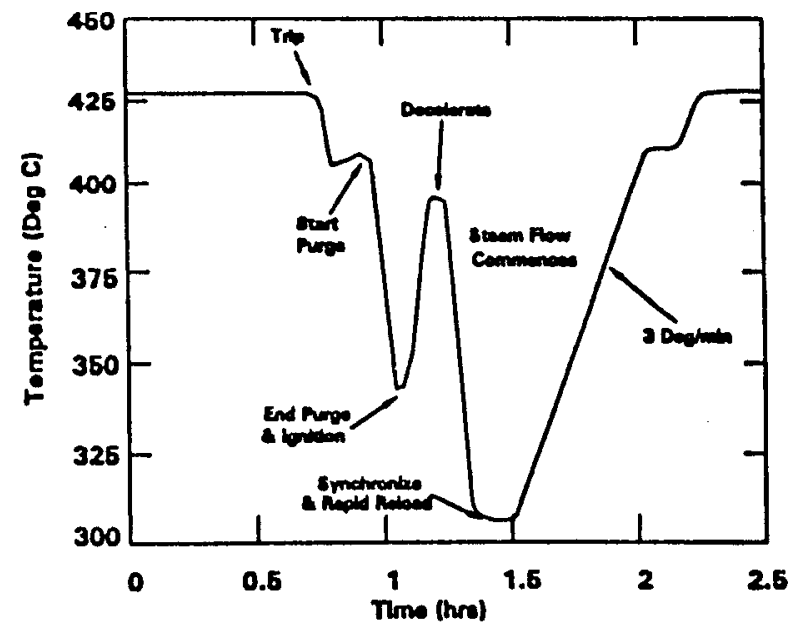

Fig. 6 Trip and immediate restart. The condensate is drained from the superheater during purge (GT initial loading rate, 2.0 per cent of the maximum continuous rating per minute)

headers at each end develop significant tensile and compressive loads when at different temperatures relative to other tubes. Thus, Figs 7a to c will develop large stresses at the tube attachment welds when other tubes in the same row are at different temperatures. The tube arrangement in Fig. 7d can accommodate the difference between the temperatures of the tubes.

Both of the foregoing problems can be substantially overcome by ensuring that the condensation formed in the superheater tubes is removed from the entire lower header without pooling throughout the purge. To do so requires either a lower header of generous bore, or many drains positioned along the length of each small bore header. Also required is an adequately sized and rated external blow-down system for HP high-temperature superheater drains.

The differences in the tube temperatures caused by progressive clearance of the condensate is especially damaging when the tubes attached to the same header have different stiffnesses. Moderate differences in the tube temperature in Figs $2 \mathrm{~b}$ and c develop extremely high stresses in the bends and attachment welds and have caused early LCF failures because small radius elbows are used with very stiff arrangement of tubes to save a few centimetres of height. To maximize the thermal flexibility, all tubes attached to the same pair of 
headers should be identical. Offset tubes utilized to avoid header end closure plugs can be omitted if a few additional centimetres of duct width are added. The end tube in Fig. 2c also serves as a drain for the upper header, which compounds the problem of removing the condensate from the blind end of the lower header in Fig. 4d.

Headers of excessive length also develop steady state temperature differences between tubes near to the inlet and outlet connections and remote tubes. Headers with centre tee connections (Fig. 2a) require a smaller bore than end connection headers (Fig. 4c) do. A further reduction in pressure drop with some reduction in the header bore is obtained by using two inlet tees. Figure $2 \mathrm{~d}$ compares the header bore and thickness using P91 and two tees with the corresponding header and a single tee in P22 material (Figs 2a to c).

Final superheater outlet panels with two or more rows of tubes attached to the header in line with the gas flow (Fig. 2a) can pick up considerably more heat in the front row tubes owing to the more exposed frontal area and turbulent flow from the GT. It is important to ensure that this is anticipated and smaller and fewer fins are used on the front row tubes in such arrangements. If
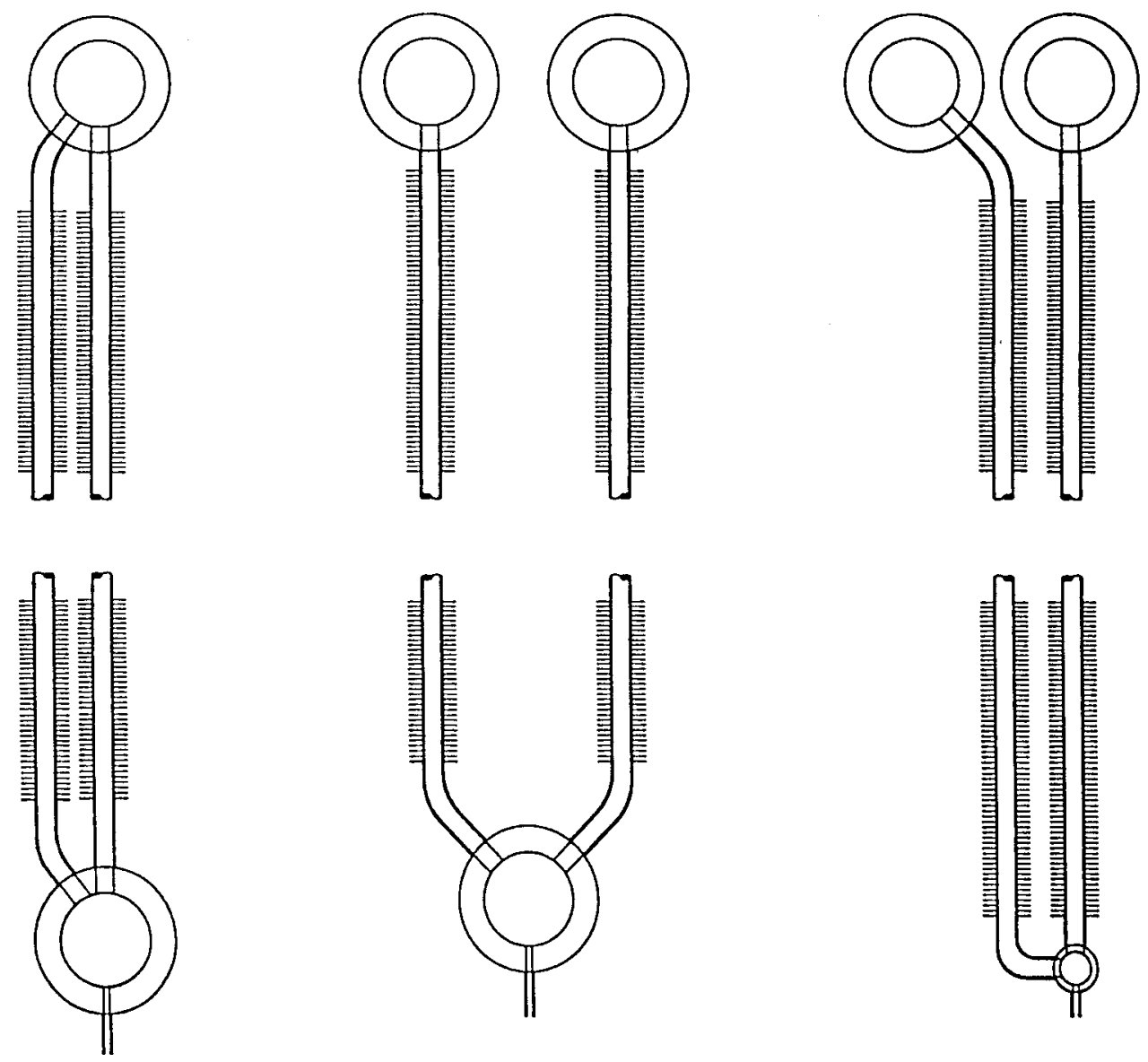

(a)

(b)

(c)
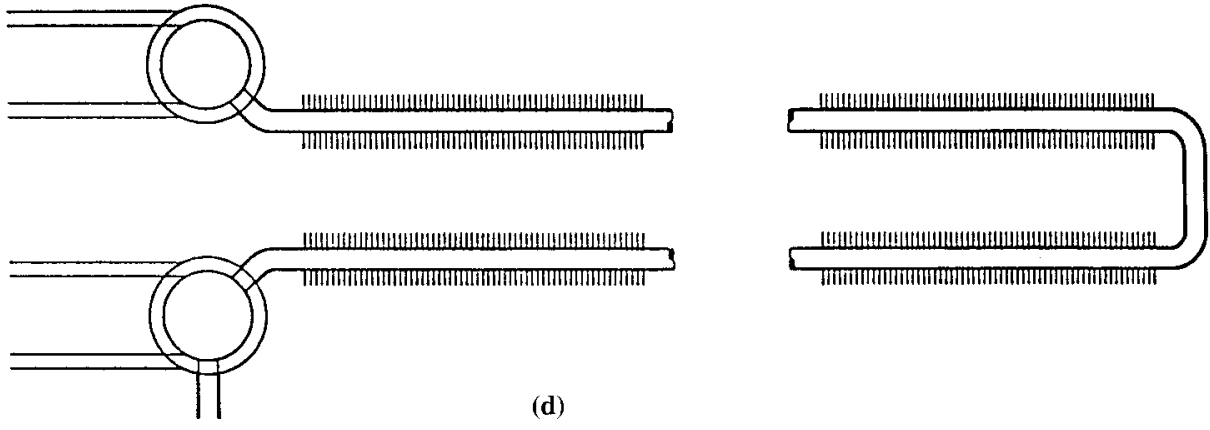

Fig. 7 Alternative superheater tube arrangements 
not, the front row tube outlet temperature can be up to $100{ }^{\circ} \mathrm{C}$ hotter than the second row tubes. This will result in local overheating at the front row tube penetration and an extremely high temperature gradient across the ligament between the two rows of tubes, high thermal stresses in steady state and an LCF concern if many starts are intended.

\subsubsection{HP steam drum and evaporator circuit}

For HP steam drums, the maximum rate of change in the pressure and saturation temperature should be determined to match the projected lifetime cold, warm and hot starts. Each design must be assessed on its merits.

Cold starts from ambient temperature are most damaging to the HP drum and superheater headers because of initial condensation heating. Starts after weekend shut-down can develop high thermal stresses if the GT is loaded too quickly.

The HP and saturation temperature step limits and large range ramp rates should be determined to match the projected lifetime number and mix of starts. It is important to keep the pressure as high as possible at all restarts by closing all isolation valves. This is beneficial to the HP superheater outlet headers as well as to the HP drum. For CCGTs intended for periods of twoshifting, HRSG isolation valves should all be motorized, opened and closed by automated sequence. The practice at some installations allows the HP to decay by leaving the drum blow-down open. This is not necessary for chemistry control since the steam flow is zero and considerably increases the LCF damage rate.

The HP evaporator circuit design requires adequate flexibility in downcomers, tubes and risers to accommodate transient temperature differences during warm restarts. Subcooling occurs in lower downcomer sections and headers particularly if parts are external to the ducts. During restarts after overnight shut-down, a significant temperature difference then develops between the downcomers and tubes which can develop high thermal stresses. Some arrangements for tube connection through risers into the steam drum can also develop large thermal stresses during starts after overnight shut-down because front row tubes return to saturation very quickly whereas rear row tubes are slow to establish circulation. Some HRSG designs have a very stiff arrangement of downcomers, tubes and risers, in which case tests and analyses should be performed before many warm starts are performed.

\subsubsection{Economizers}

Unless means are provided to pre-heat the feedwater before it enters, the low-temperature economizer inlet headers are vulnerable to quench cooling during all starts because the feedwater is not required for raising the drum level until long after GT ignition, especially on cold starts. By the time that the drum swell subsides and the feed flow is first required on any start, the gas temperature has raised the low-temperature economizer inlet header and tubes perhaps $100-150{ }^{\circ} \mathrm{C}$ above the feedwater inlet temperature. Depending on the tube arrangement at the header attachments this thermal quench may be large enough to be an LCF concern if starts become frequent.

Many designs of HRSG have HP and intermediatepressure (IP) or HP and low-pressure (LP) economizer sections which have the tubes of the two sections attached to common headers at the inlet and outlet. The headers each have an internal pressure plate to separate the two feed flows. During normal operation, the temperature difference between the two sets of tubes is moderate. During all starts, the feed flow is not required to the HP and IP (or the HP and LP) drums at the same time. As the swell subsides and the flow commences to one of the drums, temperature differences of $150^{\circ} \mathrm{C}$ have been measured between the stagnant tubes which are at the gas temperature and the tubes with cool feed flow established (Fig. 8). This results in high tube loads at the attachment welds adjacent to the division plates and also high hoop stresses in the header at the same location.

Failures at tube attachment welds adjacent to division plates and in division plate welds have occurred after 100-200 starts on many economizers with common headers. Tube loads can be eliminated by separating the lower header into two sections; however, the upper header still has high hoop stresses. Common headers are not suitable anywhere in HRSGs intended for large numbers of starts.

\subsection{Corrosion}

Corrosion damage is not limited to larger HRSGs nor is it readily apparent that they are suffering from it to a greater extent than their older smaller siblings. With the exception of flow-assisted corrosion (FAC), where many cases have occurred when design practices suggest that none should, corrosion is well understood and therefore avoidable.

Although the steam temperatures and heat flux have increased in larger HRSGs, they are still within the range where conventional and reliable treatment systems are effective. The corrosion which most often damages HRSGs is long term or intermittent and has gone undetected by the operator. The best corrosion management programme will only prevent damage if it is applied without lapses. This means that operators must have accurate chemistry data, they must be trained to interpret it and authorized to act on it, and it must be available to them at an interval which is 


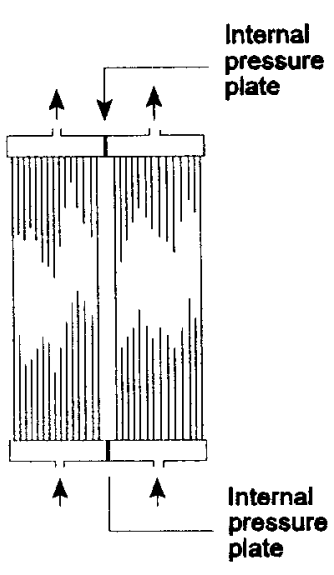

(a) Tubes at equal temperature

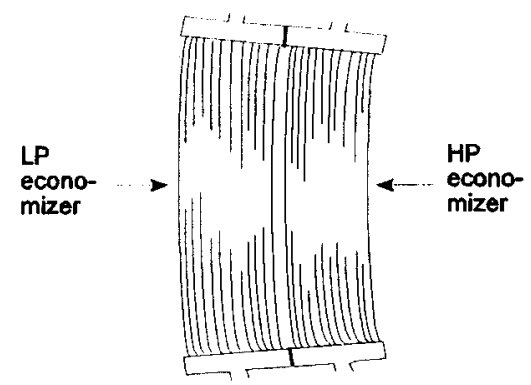

(b) Distortion from cold feed flow to one side; other side stagnant at gas temperature

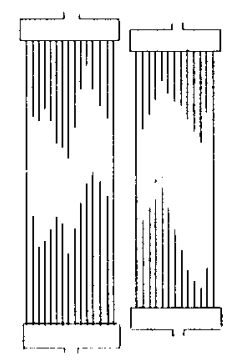

\section{(c) Expansion when headers are separated}

Fig. 8 An exaggerated representation of the thermal distortion of the common (shared) headers-tube arrangement

shorter than the duration of excursions which may occur.

Many plants depend on one or more chemistry technicians to collect and interpret chemistry data while the operators have limited knowledge of the subject. This method risks undetected defects in the plant's treatment programme and occasional periods of operation outside of limits.

\subsubsection{Flow-assisted corrosion}

FAC, or erosion-corrosion, generally affects the LP evaporator upper bends and sometimes the IP evaporators. Economizer upper hairpin bends on HRSGs which are prone to steaming during starts are also susceptible. A typical design solution is to limit the velocity of the steam-water mixture at the upper bends below some threshold. The tube velocity limits are sometimes exceeded during starts because very high circulation can occur transiently in front row tubes before circulation is established in all tubes. An alternative solution is to fit $1 \% \mathrm{CrMo}$ upper bends in carbon steel tubes of LP and IP evaporators and economizers.

\subsubsection{Low-temperature gas-side corrosion}

Gas-side corrosion affects tubes operating below the flue gas dew point owing to the low inlet feedwater temperature. When designing a new plant the inclusion of an elevated thermal deaerator can avoid this problem while also giving the benefit of lower dissolved oxygen at start-up, especially if some two-shifting is anticipated. Existing plants may use the alternative of adding external feedwater pre-heaters using steam or water coils.

\subsubsection{Water- and steam-side chemistry management}

Consistent management of water- and steam-side chemistry is essential for long-term reliability and durability of the HRSG. HP boilers are very unforgiving of even isolated major chemistry excursions. The thin tube walls used in all HRSGs leave no practical corrosion margin for even occasional chemistry excursions. Many CCGT stations have no chemist experienced with HP boilers. Reliable expertise from contractors can be obtained but alone cannot be counted on to prevent excursions. Continuous sampling and monitoring with real-time data presentation usable by the operators, and not chemical technicians, are viable and affordable. When combined with support by reputable expert consultants and/or contractors, effective preventive maintenance and adequate operator training, continuous monitoring is very effective.

Post-construction chemical cleaning of water-side components and a steam purge of steam pipes are extremely important to long-term durability of HRSGs. Many HRSGs that were not thoroughly cleaned have suffered corrosion and freeze damage from failure to drain completely during shut-down because of the clogging of maintenance drains.

Although less frequently used today because of the pressure to cut costs, an elevated separate thermal deaerator offers multiple benefits when two-shift operation is required. Most significantly, it ensures low dissolved oxygen on starts even after breaking the vacuum. 
Condensate polishing is also beneficial for start-ups of two-shift CCGTs by reducing blow-down. The water saved may justify the cost of the polisher.

\subsection{Other thermal-mechanical problems}

\subsubsection{HCF problems}

Large GTs with cold end drives and axial exhaust gas flow directed at the transition duct and superheater tubes have increased HCF problems. Successful support of structures in the gas path nearest to the GT is a challenge which requires greater attention. There have been many reports of HCF failures of superheater top supports and additional vibration restraints have been necessary for tubes in superheater panels. HCF is also a persistent problem with restraints, duct burners and supports, inlet diffuser plates, flow guides, thermocouples, drain pipes, casing seals and duct liners. Twoshifting may exacerbate the $\mathrm{HCF}$ problems because it introduces wider flow conditions which will produce a wider range of excitation frequencies.

\subsubsection{Problems to be avoided with cold and hot HRSG inlet duct and casings}

Both hot and cold casing design concepts are difficult to execute to be free of LCF durability issues. Cold casings only work if the insulation integrity is good with no weak points. Two-shifting applies cyclic loads to the pins securing insulation and the hot liners. Stainless steel pins welded to carbon steel ducts are vulnerable to stress corrosion at the attachment welds and their integrity needs to be monitored for early distress.

Hot casings also need careful design to ensure that the stiffeners all heat and cool at the same rate as the casings. Poorly designed and fabricated hot casings can develop into a major problem on HRSGs subjected to two-shift operation. External stiffeners can quickly cause LCF cracks. The challenge is to design external supports for the casings and ducts that will not crack by LCF at the attachment welds.

\subsubsection{Expansion joints at HRSG inlet}

As the GT exhaust temperatures increase, so does the severity of temperature gradients in the expansion joints. Rectangular expansion joints are especially difficult to design for GTs with the highest exhaust temperatures, even for a moderate number of cycles. Very large temperature differences have been measured between the inner and outer flanges of the expansion joints during GT starts. Flanges buckle after a very few cycles. Once a gas leak develops, the hot gas rapidly fails the joint material. Circular joints are more durable but are still likely to show distress after moderate starts. On outdoor HRSGs, it is important to prevent rain from quenching hot expansion joint flanges.

\subsubsection{Over-spraying at HP steam attemperator during part-load operation}

On some CCGTs the position of the superheater attemperator has been selected too early in the steam path design. This is demonstrated by the requirement to over-spray, sometimes reaching saturation temperature, during part-load conditions. The steam temperature is uncontrollable and swings wildly. In addition, water droplets concentrate in the few tubes with the least resistance or direction change. This results in significant differences between the tube temperatures in the final superheater which, unless corrected, will eventually lead to LCF failures at the attachment welds.

These deficiencies result from specifying a wide range of conditions, fuels, etc., for which the design steam temperature must be achieved, resulting in excess surface (and higher HRSG cost) for normal operation at higher ambient temperatures. The problem is particularly evident with those GTs with an elevated GT exhaust temperature at part load for the purpose of extending the turn-down ratio with pre-mix combustion.

For new installations, these problems are avoided by a thorough analysis of the performance at all loads. The purchaser must then select what compromises should be made. For existing units with this deficiency, some final superheater surface must be sheathed, or removed, to reduce the heat transfer surface sufficient to maintain at least $10{ }^{\circ} \mathrm{C}$ superheat after attemperation at all stable operating conditions.

\subsection{Stratification of gas in the HRSG during the pre-start purge}

Increasingly severe transition duct expansions are being used to reduce the space and cost. A transition duct with a $45^{\circ}$ ceiling slope at base load has gas at the inlet to the final superheater about $20^{\circ} \mathrm{C}$ cooler in the upper part of the duct than in the lower part. Some recent HRSGs have gone even steeper. The impact of stratification of the gas temperature on the tube metal temperatures and heat transfer needs to be assessed.

The other notable fact is that, during the purges prior to GT ignition, the reduced GT exhaust flow passes only through the lower part of the superheater. This defeats the object of the purge which is intended to purge combustible gases from the HRSG before GT ignition. Since natural gas and most volatiles released from distillate fuel oil which may have collected in the insulation are lighter than air, it is particularly important for the purge to flush out any combustibles that 
have collected in the dead spaces at the top of the duct. Figure 9 compares inlet ducts on two HRSGs behind $150 \mathrm{MW}$ GTs. On the upper HRSG, the gas temperature during a purge is reasonably uniform with the temperature of the upper region of the duct about $20^{\circ} \mathrm{C}$ below that of the lower region whereas, in the HRSG with the steeper transition duct, the temperature in the upper portion of the duct remains constant throughout a 15 min purge while at the lower level the gas temperature fell $120^{\circ} \mathrm{C}$ below that in the upper level.

There appears to be a need for a thorough review of the purpose of HRSG purges and under what circumstances there is any risk of ignition of combustibles in the upper duct. Many operators may not be accomplishing what they intend if their HRSG inlet ducts have large transition angles.

\section{CONCLUSION}

The onus is very much with the owner of a new CCGT project to clarify the requirements when specifying what is and is not acceptable in the design of the HRSG. All HRSGs are designed to a boiler design code and none of the weaknesses highlighted in this paper is excluded by BS or ASME, which are the two boiler codes most widely used internationally. Neither code
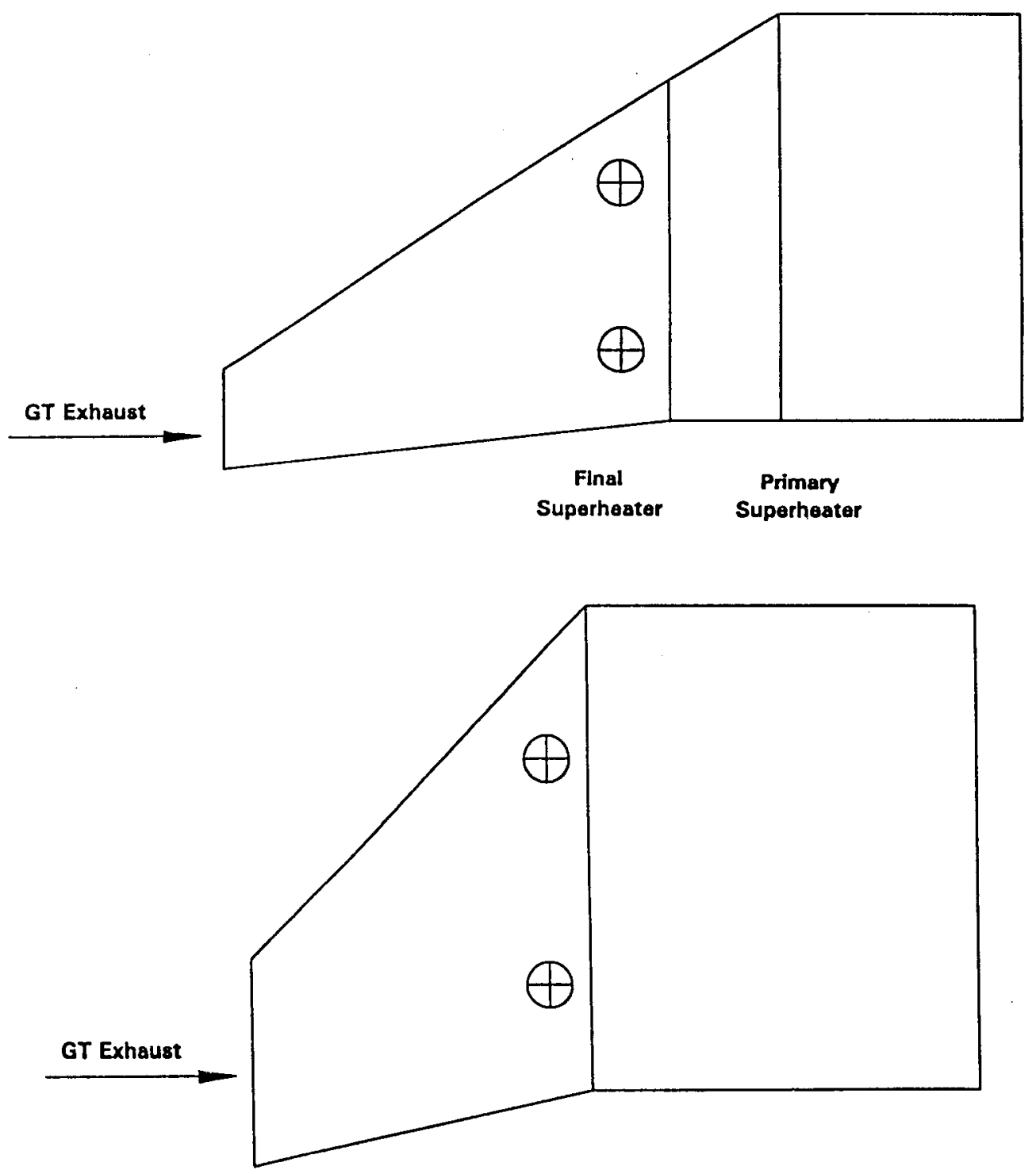

Ges side thermocouple

Fig. 9 The transition duct effect on the distribution of gas into the superheater 
mandates analysis of transient conditions. If the owner is confident that the CCGT:

(a) will always operate continuously at or near base load conditions without any disruption from the grid control, fuel supply pressure, fuel quality, steam upsets by cogeneration host, etc.,

(b) will perform no more than one cold start per year required for the GT combustion or hot gas path inspection,

(c) will perform no off-line water washes of GT to maintain the output and efficiency between annual outages and

(d) will be engineered, commissioned, operated and maintained to industry best practices, so that trips are restricted to not more than two per year,

then the CCGT will accumulate a lifetime of only 30 cold starts and not more than 50 trips, in which case almost any HRSG designed to ASME or BS is probably acceptable even with large GTs. However, it is important for purchasers to realize that cold starts and hot restarts after trips are, by an order of magnitude, the most severely damaging events for HRSGs with some of the weaknesses described in this paper, as evidenced by the occurrence of LCF failures in about 100 cycles.

With state-of-the-art and continuously advancing GT and CCGT technologies it is unrealistic to expect such a low number of starts even in the unlikely event that the installation is assured of a lifetime of base load operation. Trips and unplanned forced outages are not just a concern with the large highly rated GTs. Many trips are caused by the balance of plant equipment supplied by very competitively bid low-cost EPC contracts.

HRSG reliability and durability can be considerably enhanced, at moderate installed cost, by adoption of the recommendations in this paper, but this will not happen unless the owner is concerned to eliminate weaknesses in low-cost designs of HRSGs. The pressure on HRSG manufacturers from purchasers, whether owners or EPC contractors, is to lower installed cost and not to improve the reliability and durability, which usually is not a major issue for the first 3 or 4 years of service and, therefore, not a warranty concern.

Some of the weaknesses described can be eliminated by small increases in width or height in the HRSG. Ironically some owners now require, and pay extra for, more space to make repair of tube failures less difficult. Yet the same extra costs could be much more effectively applied to get rid of the underlying generic causes of failures. Once tube failures occur in tightly packed HRSG tube bundles, repair usually involves extensive cutting in and welding out to get access to the failed tubes, or cutting windows in the headers. Whichever occurs, it considerably reduces the durability of all the disturbed parts with patch welds made in very difficult conditions and no heat treatment. The extra cost should be used to obtain a simpler, more thermally flexible HRSG, manufactured to higher quench cooling standards, and thereby to eliminate the need to repair any tube failures.

Prevention of damage in the first place is clearly worth significant effort. Coordination of the CCGT's duty cycle, operating practices and design can result in predictably lower life costs, if at the expense of slightly greater first cost.

HRSGs designed with many of the features presented in this paper have been installed for a lifetime of daily two-shift operation. They have been designed using conservative analyses based on dynamic simulation of conditions during all transients, verified by measurement of actual conditions in service and have established the capability to perform several thousands of starts after overnight and weekend shut-downs. The key to achieving this objective was substantial reduction in the thickness of superheater headers to mitigate the considerably greater LCF damage caused to thickwalled headers by the cold starts and hot starts after trips. If this objective is not achieved, there is very little LCF life capability remaining after quite low numbers of cold starts and hot restarts after trips to accommodate the relatively low LCF damage following overnight shut-downs. The purpose and efficacy of pre-start purges on HRSGs with large inlet transition duct angles should be reviewed.

\section{RECOMMENDATIONS}

\subsection{New installation}

High thermal flexibility is attainable in new CCGT installations by appropriate specification of the HRSG. The key elements are as follows.

\subsubsection{For superheaters}

1. Use P91 or equivalent material instead of the more widely used P22 for the superheater outlet headers and outlet manifold to minimize the wall thickness.

2. Specify the extended design life for creep to limit the lifetime creep factor to not more than 60 per cent to permit some LCF damage. Even then LCF must be limited to a lifetime factor of about 5 per cent (Fig. 1).

3. Specify full penetration welds for tube to header attachment (Fig. 10).

4. Limit header length or install two tees per header to reduce the bore and to maintain low steam velocities to ensure uniform flow and temperature rise through all the tubes at steady state and especially during starts. 


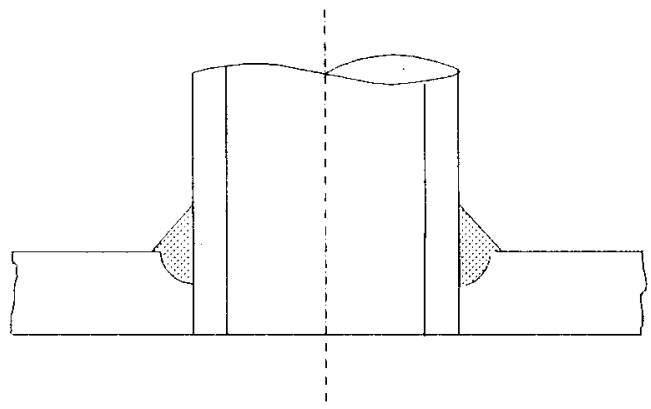

(a) Partial penetration weld

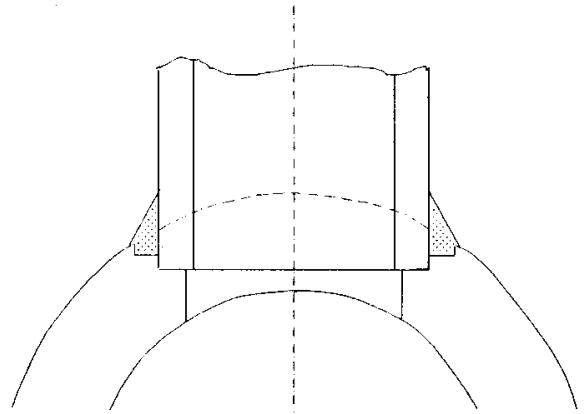

(b)
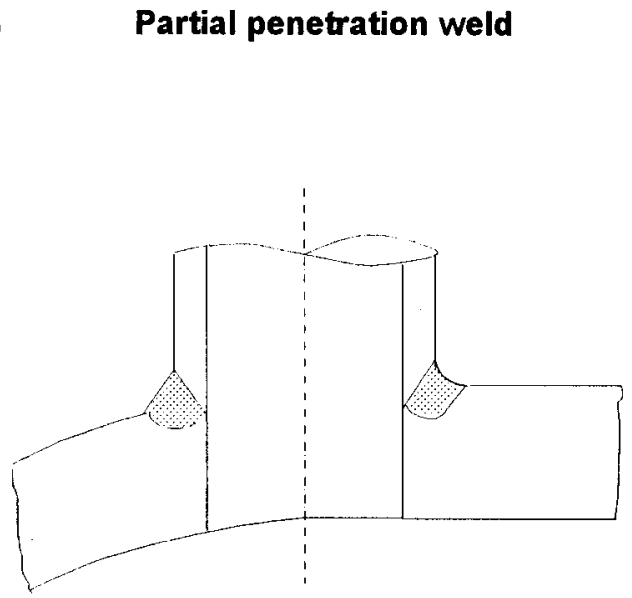

(c)

\section{Full penetration weld}

Fig. 10 Partial and full penetration welds

5. Provide adequately sized and located drains on the lower superheater headers to remove the condensate at the saturation temperature at the maximum rate of condensation without pooling.

6. Provide a blow-down tank and adequately size for blow-down of all the superheater sections throughout the purge.

7. Automate the sequenced control of the superheater drain valves during starts and shut-down.
8. Ensure that the tubes have sufficient flexibility to accommodate the maximum difference between the tube temperatures attached to the same headers.

9. Exclude tube anomalies that under any operating condition can develop temperature differences between the tubes.

10. Ensure that the superheater attemperator flow at any normal operating load does not require spray down to saturation. Relocate the attemperator closer to the superheater outlet, if necessary, to achieve this, or consider a second-stage attemperator after the final superheater.

\subsubsection{For the HP drum and evaporator circuit}

1. Ensure adequate flexibility in the downcomers, evaporator headers, tubes and risers to the drum to accommodate subcooling during warm restarts without excessive thermal stresses.

2. Establish and quantitatively verify limits to the HP saturation temperature step and ramp the change rates for the HP drum, downcomers and risers.

3. Specify the low pinch point temperature difference between the saturation and gas outlet for the HP, IP and LP evaporators to minimize the risk of steaming in economizers during start-ups.

\subsubsection{For economizers}

1. Prohibit the use of shared and common headers with internal pressure plates for different sections of the economizer.

2. Specify full penetration welds for the tube to the header attachments.

3. If periods of two-shift or weekend shut-downs are planned, decide on means of pre-heating the condensate before the low-temperature economizer; this is required to avoid quench cooling when the feed flow is established, which occurs long after firing commences.

4. Separate deaerator after the condenser extraction pump is recommended for units intended for periods of two-shift operation or weekend shut-down. The deaerator overcomes concerns for quench cooling economizers during starts and also ensures a low oxygen content during starts after breaking the condenser vacuum during shut-down.

5. Locate the HP, IP and LP feed-regulating valves after the economizer sections to permit recirculation during starts.

\subsubsection{Others}

1. Specify means to seal the steam turbine glands and to raise the condenser vacuum before the GT purge is completed to ensure that the steam turbine bypass systems are in service shortly after GT ignition and 
are utilized to control the rate of rise in the high and low steam pressures during all starts.

2. Pay attention to ducts and casings, which should not be a problem but, when poor design or fabrication occurs, ducts can become a major maintenance activity in hot sections of the HRSG. Attention to detail is important whether cold or hot casings are used. Two-shift operation will quickly reveal any weaknesses.

3. Analyse in detail the expansion joints at the HRSG inlet which are subject to severe heating and cooling ramps by all starts and trips or shut-downs. Rectangular joints are particularly vulnerable to very early LCF failure and rapid degradation. On outdoor installations, prevent rain from quenching expansion joints.

4. Ensure that seals between the tube bundles and duct casings are tight. Small gaps are significant to HRSG performance and lead to overheating of lower-temperature tubes.

5. Ensure that the concentrated mean stresses in the tube bundle supports are low to accommodate the vibration forces transmitted from the tube bundles exposed to the turbulent gas flow from large axial exhaust GTs.

\subsubsection{Corrosion-related issues}

1. Ensure rigorous feedwater and steam-side cleaning prior to first start-up.

2. Ensure that the IP and LP evaporator tube velocities at the outlet bends are well below the threshold for erosion-corrosion.

3. Reduce the risk of erosion-corrosion substantially by installing $1 \% \mathrm{CrMo}$ bends at critical locations of the LP and IP evaporator and the LP and IP economizers.

4. Ensure that the inlet feedwater to the pre-heater or economizers is pre-heated above the gas or oil dew point.

5. Utilize continuous sampling and data logging with real-time data to the operator and support from consultants and/or contractors who are experts in power station chemistry.

\subsection{Design modifications for existing installations}

1. Install or upgrade superheater drains for the re- moval of all the condensate from the superheater. An additional blow-down tank may be required. Additional superheater drains are required on many HRSG designs.

2. For units with different economizer sections sharing common upper and lower headers, either physically separate the lower header or devise modifications to the external systems and/or operating procedures to eliminate the significant transient temperature differences between the two sections. Various alternatives are available.

3. Devise a means of eliminating the quench cooling of low-temperature economizers when the first feed flow is established some time after the high gas temperatures prevail at the economizers during all starts.

4. Eliminate gas-side condensation at the low-temperature economizer inlet by adding pre-heating of the feedwater.

\subsection{Improvements to operating practices to minimize LCF}

1. Establish a life management strategy based on the projected lifetime operating hours (for creep) and numbers for each of cold, warm, hot and very hot restarts.

2. Investigate the recommendations in Section 3.3 above.

3. Review the operating procedures to reduce the temperature steps and gradients in the superheater and HP drum evaporator circuits. Conduct trial starts to assess the sensitivity of the HRSG to LCF resulting from GT loading rates.

\section{REFERENCES}

1 Pearson, J. M. Assessment of the design of critical components and operating methods for reliable two-shifting of CCGTs and fossil-fired units. In Proceedings of the Seminar on The Two-Shifting of CCGT and Fossil Fired Stations, December 1995 (Mechanical Engineering Publications Limited, London).

2 Jesson, J. E. The fatigue life of heat recovery steam generators. In Proceedings of the Seminar on Commissioning and Operation of Combined-Cycle Plant, November 1994 (Mechanical Engineering Publications Limited, London). 